\title{
PLANOS MUNICIPAIS DE SANEAMENTO, AÇÕES DE EMERGÊNCIA E PANDEMIA DE COVID-19: OS CASOS DE CAMPINAS/SP E HORTOLÂNDIA/SP
}

\section{MUNICIPAL SANITATION PLANS, EMERGENCY ACTIONS AND COVID-19 PANDEMIC: THE CASES OF CAMPINAS/SP AND HORTOLÂNDIA/SP}

\author{
Maria Flávia de Araujo Gottardello ${ }^{1}$ \\ Mestranda em Arquitetura e Urbanismo no Programa de Pós-Graduação da Pontifícia Universidade Católica de \\ Campinas. Advogada. Bacharela em Direito também pela PUC-Campinas. \\ Patrícia Rodrigues Samora ${ }^{2}$ \\ Doutora em Arquitetura e Urbanismo, docente pesquisadora no Programa de Pós-Graduação em Arquitetura e Urbanismo \\ da Pontifícia Universidade Católica de Campinas.
}

\section{E-mail1: maria.fag2@puccampinas.edu.br}

\begin{abstract}
RESUMO
Os Planos Municipais de Saneamento devem elencar respostas emergenciais que forneçam água potável para a população carente em saneamento durante desastres, como a pandemia de Covid-19. Este artigo apresenta os casos de Campinas/SP e Hortolândia/SP, objetivando discutir se os planos de saneamento vigentes trazem respostas para garantir o fornecimento emergencial de água aos carentes em saneamento. Visa, também, apresentar as medidas adotadas pelas prestadoras dos serviços frente à pandemia de Covid-19, para discutir se promovem o direito à água. Como método, fez-se revisão bibliográfica para compreender o papel do planejamento sanitário no combate às urgências que extrapolam os aspectos técnicos e operacionais; leitura crítica dos planos de saneamento; identificação das respostas das prestadoras frente à pandemia de Covid-19. Os resultados apontam que as ações de combate à pandemia são insuficientes e que as respostas emergenciais dos planos não atendem os carentes em água potável.
\end{abstract}

\begin{abstract}
The Municipal Sanitation Plans must list emergency responses that provide clean water to the population in need of sanitation during disasters, like the Covid-19 pandemic. This article presents the cases of Campinas/SP and Hortolândia/SP, aiming to discuss whether the current sanitation plans bring answers that guarantee the emergency water supply to the needy in sanitation. It also aims to present the measures adopted by service providers against the Covid-19 pandemic, to discuss whether they promote the right to water. As a method, a literature review was carried out to understand the role of health planning in combating emergencies that go beyond technical and operational aspects; critical reading of sanitation plans; identification of providers' responses to the Covid-19 pandemic. The results show that the actions to combat the pandemic are insufficient and that the emergency responses of the plans do not serve those in need of drinking water.
\end{abstract}

Palavras-chave: Direito humano à água. Desastres. Planejamento. Planos de saneamento.

Key words: Human right to water. Disasters. Planning. Sanitation Plans.

\section{INTRODUÇÃO}

Os Planos Municipais de Saneamento, previstos na Lei Federal n ${ }^{\circ}$ 11.445/07 (BRASIL, 2007), são importantes para guiar a atuação das prestadoras dos serviços de saneamento básico. Isso porque, devem trazer, além do diagnóstico de todos os componentes do saneamento básico (abastecimento de água, esgotamento sanitário, limpeza urbana e manejo de resíduos sólidos, drenagem e manejo de águas pluviais urbanas), com informações sobre a oferta e o déficit dos serviços, os objetivos e metas para universalização do acesso aos serviços (FUNDAÇÃO NACIONAL DE SAÚDE, 2014). É por meio deles que as prestadoras dos serviços de saneamento devem pautar suas ações, promovendo o 
direito à água e saneamento àqueles que ainda não têm. Ainda, os Planos Municipais de Saneamento devem conter ações para emergências e contingências, para responder aos eventos anormais, podendo ser "previstas considerando eventuais problemas já observados na prestação adequada dos serviços" (ibidem, 2014, p. 35), bem como para "prever possíveis desastres em função da observação e avaliação dos técnicos peritos" (ibidem, 2014, p. 35).

Contudo, entende-se que as ações emergenciais, previstas nos planos de saneamento, não devem considerar apenas os aspectos técnicos e operacionais dos serviços, na medida em que determinadas emergências, como a pandemia de Covid-19, não são de caráter técnico e potencializam as vulnerabilidades daqueles que são carentes dos serviços sanitários. Neste caso, as pessoas sem os serviços de abastecimento de água, bem como aquelas que são alvos de interrupção no fornecimento de água potável pela impossibilidade de pagar as tarifas e, ainda, aquelas que residem em locais onde falta água de maneira regular estariam mais vulneráveis em relação ao vírus, porquanto a adoção de métodos higiênicos preventivos restaria prejudicada.

Moretti et al. (2013, p. 305) indicam circunstâncias que "potencializam a necessidade de formulação de um plano para situações emergenciais" e destacam, por exemplo, aquelas em que parte da população não tem condições de pagar a tarifa pela água consumida. Freitas et al. (2020) explicam que exposição ao perigo, vulnerabilidade e baixa capacidade de resposta são condições para a ocorrência do desastre. Na existência de um perigo, como epidemia de dengue, risco de desabastecimento e doenças causadas por vírus, as pessoas mais pobres, que residem em bairros marginalizados e assentamentos precários, se encontram em situação de vulnerabilidade socioeconômica e possuem baixa capacidade de resposta, em razão da precariedade ou falta de acesso à água potável, que não permite a adoção de medidas higiênicas e de outras ações cotidianas essenciais para se viver com dignidade. Os Planos Municipais de Saneamento deveriam, portanto, no ponto das ações emergenciais e de contingência, considerar como anormal aquelas situações em que o fornecimento de água potável pode atuar como resposta apta a diminuir os riscos que colocam a população carente deste serviço em maior vulnerabilidade, como é o caso da pandemia de Covid-19. Isso, é claro, sem perder de vista a universalização. Importante que os planos municipais, que privilegiam as matrizes tecnológicas (HÉLLER, 2013), passem a considerar como emergenciais situações não estão apenas relacionadas aos aspectos operacionais e técnicos.

Este artigo apresenta estudo de caso de Hortolândia e Campinas, integrantes da Região Metropolitana de Campinas ${ }^{1}$, objetivando: demonstrar o que os Planos Municipais de Saneamento (PMSB) vigentes nessas cidades entendem como ações emergenciais envolvendo o serviço de abastecimento de água; identificar as respostas emergenciais relacionadas a este serviço; discutir se as ações estabelecidas poderiam auxiliar no combate à pandemia de Covid-19; apresentar as respostas que foram dadas pelas prestadoras dos serviços de saneamento atuantes nessas cidades (Companhia de Saneamento Básico do Estado de São Paulo - SABESP; Sociedade de Abastecimento de Água e Saneamento de Campinas - SANASA ${ }^{2}$ ). A escolha das cidades de Hortolândia e Campinas se deu porque: Campinas é o município-sede da região metropolitana; a região noroeste de Campinas, que é limítrofe à cidade Hortolândia, é marcada por processo de periferização da pobreza e pela precariedade habitacional (CAMPINAS, 2011), sendo que estas cidades estão entre os municípios desta região metropolitana com maior déficit habitacional (AGÊNCIA METROPOLITANA DE CAMPINAS, 2018), o qual tem ligação direta com o déficit de saneamento (FURIGO, 2020).

Como resultado, aponta-se que, nas cidades avaliadas, os planos municipais de saneamento não trazem respostas para garantir água potável à população carente deste serviço. Além disso, aponta-se

\footnotetext{
${ }^{1}$ A Região Metropolitana de Campinas é composta por 20 municípios: Americana, Artur Nogueira, Campinas, Cosmópolis, Engenheiro Coelho, Holambra, Hortolândia, Indaiatuba, Itatiba, Jaguariúna, Monte Mor, Morungaba, Nova Odessa, Paulínia, Pedreira, Santa Bárbara d'Oeste, Santo Antônio de Posse, Sumaré, Valinhos e Vinhedo. Fonte: PDUI. Plano de Desenvolvimento Urbano Integrado: Região Metropolitana de Campinas. 2018.

2 A SABESP é classificada como sociedade de economia mista estadual; a SANASA como sociedade de economia mista municipal.
} 
que as ações de combate à pandemia de Covid-19 não seriam suficientes. Este artigo é relevante, pois analisa criticamente os Planos Municipais de Saneamento e sua capacidade de manejar emergências sanitárias.

\section{METODOLOGIA}

Fez-se revisão bibliográfica sobre a importância do planejamento dos serviços de abastecimento de água no manejo de emergências sanitárias, a exemplo da pandemia de Covid-19. Fez-se leitura crítica dos Planos Municipais de Saneamento vigentes em Hortolândia e Campinas, identificando quais são as respostas emergenciais previstas para o abastecimento de água, qual a população-alvo do plano emergencial e se estão relacionadas aos aspectos técnico-operacionais ou se visam garantir o abastecimento emergencial de água aos carentes em saneamento. Por meio da Lei de Acesso à Informação (BRASIL, 2011) foi aberto procedimento administrativo junto à SABESP, para obter as respostas dadas frente à pandemia de coronavírus. Em relação à SANASA foi feita coleta de informações em seu sítio eletrônico. Tais informações foram sistematizadas em quadro e avaliadas considerando que as medidas de combate à pandemia devem atender a população vulnerável, que habita espaços urbanos onde não há acesso à água ou sofre com intermitência e que pode ter dificuldades para pagamento das tarifas de água.

\section{DISCUSSÃO E RESULTADOS}

O Quadro 1 apresenta considerações acerca das ações emergenciais previstas nos Planos Municipais de Saneamento (PMSB) vigentes nas cidades supramencionadas.

Quadro 01: ações emergenciais previstas nos Planos Municipais de Saneamento vigentes em Hortolândia e Campinas.

\begin{tabular}{|c|c|c|}
\hline Itens de Avaliação & Hortolândia & Campinas \\
\hline $\begin{array}{l}\text { O que o PMSB entende por } \\
\text { emergência/contingência? }\end{array}$ & $\begin{array}{c}\text { Não conceitua contingência e emergência para } \\
\text { água potável }\end{array}$ & $\begin{array}{l}\text { "Evento crítico": aquele que exige adoção } \\
\text { de respostas, procedimentos de "controle } \\
\text { e combate do incidente" e } \\
\text { estabelecimento de responsabilidades. } \\
\text { O plano de saneamento também } \\
\text { menciona o "Plano Municipal Integrado } \\
\text { de Gerenciamento de Assistência } \\
\text { Humanitária para Situações de Desastres } \\
\text { - PMIGAHD", que define emergência } \\
\text { como "situações que exigem intervenção } \\
\text { imediata de profissionais treinados" eque } \\
\text { podem ser consideradas como situações } \\
\text { anormais, "provocadas por desastres, } \\
\text { causando sérios danos à comunidade } \\
\text { afetada, inclusive à incolumidade ou à } \\
\text { vida de seus integrantes". }\end{array}$ \\
\hline Objetivo das ações emergências & $\begin{array}{l}\text { Apresentar a infraestrutura sanitária existente e } \\
\text { descrever os procedimentos adotados para } \\
\text { manter a qualidade da água, identificando as } \\
\text { áreas onde não há abastecimento de água. }\end{array}$ & $\begin{array}{l}\text { É "estabelecer as ações emergenciais e de } \\
\text { monitoramento e controle"; apresentar } \\
\text { "um descritivo físico e de aspectos } \\
\text { operacionais, métodos, forma e } \\
\text { frequência de monitoramento"; definir } \\
\text { "os responsáveis pelas ações e } \\
\text { treinamentos necessários para a garantia } \\
\text { do abastecimento contínuo e com } \\
\text { qualidade"; "minimizar os riscos que } \\
\text { podem afetar a qualidade" dos serviços } \\
\text { "seja com relação aos aspectos físicos, } \\
\text { químicos ou de fornecimento". }\end{array}$ \\
\hline
\end{tabular}

${ }^{3}$ CAMPINAS (Município). Decreto no 17.851/2013. Dispõe sobre o Plano Municipal Integrado de Gerenciamento de Assistência Humanitária para situações de desastres. Campinas, 2013. 


\begin{tabular}{|c|c|c|}
\hline $\begin{array}{c}\text { Emergências elencadas no PMSB } \\
\text { para o serviço de abastecimento de } \\
\text { água }\end{array}$ & Não foram elencadas emergências. & $\begin{array}{l}\text { Eventos críticos que podem prejudicar o } \\
\text { funcionamento do sistema de } \\
\text { abastecimento de água. O PMIGAHD } \\
\text { também não elenca emergências que } \\
\text { podem ocorrer. }\end{array}$ \\
\hline $\begin{array}{c}\text { Respostas apresentadas frente às } \\
\text { emergências }\end{array}$ & $\begin{array}{l}\text { Alocação de recursos financeiros; } \\
\text { manutenção e modernização do sistema de } \\
\text { abastecimento de água }\end{array}$ & $\begin{array}{l}\text { Procedimentos internos, metodologias de } \\
\text { monitoramento da infraestrutura do } \\
\text { sistema de abastecimento de água. O } \\
\text { plano emergencial apenas elenca, por } \\
\text { meio de códigos internos da prestadora } \\
\text { dos serviços, os procedimentos a serem } \\
\text { adotados. Não há explicação do conteúdo } \\
\text { desses códigos. PMIGAHD: garantia } \\
\text { emergencial de água potável às vítimas da } \\
\text { emergência. Não elencou as formas pelas } \\
\text { quais isso pode ocorrer, prazo a ser } \\
\text { cumprido, quantidade de água a ser } \\
\text { fornecida. }\end{array}$ \\
\hline Público-alvo das respostas & $\begin{array}{l}\text { Pessoas que já possuem acesso aos serviços de } \\
\text { abastecimento de água, na medida que apontam } \\
\text { apenas para a necessidade de monitoramento e } \\
\text { modernização do sistema. }\end{array}$ & $\begin{array}{l}\text { Pessoas que residem nos locais onde há } \\
\text { infraestrutura dos serviços de } \\
\text { abastecimento de água, pois tratam } \\
\text { apenas da infraestrutura já existente. } \\
\text { PMIGAHD: qualquer pessoa que tenha } \\
\text { sido atingida pela emergência, desastre ou } \\
\text { calamidade pública. }\end{array}$ \\
\hline $\begin{array}{l}\text { Há preocupação em prover água } \\
\text { para aqueles que não têm acesso às } \\
\text { redes de abastecimento, durante } \\
\text { emergências sanitárias? }\end{array}$ & NÃO & NÃO \\
\hline
\end{tabular}

Fonte: elaboração própria, 2021, a partir dos Planos Municipais de Saneamento vigentes em Hortolândia ${ }^{4}$ e Campinas ${ }^{5}$.

O Quadro 2 apresenta as ações adotadas pelas prestadoras dos serviços de saneamento de Campinas e Hortolândia durante a pandemia de Covid-19.

Quadro 2: respostas adotadas pelas prestadoras dos serviços de saneamento de Hortolândia e Campinas frente à pandemia de Covid-19

\begin{tabular}{|c|c|}
\hline Hortolândia & Campinas \\
\hline $\begin{array}{l}\text { Instalação de quatro pontos para lavagem das mãos (UPA Jd. } \\
\text { Amanda, UPA Jd. Rosolém, UPA Nova Hortolândia e no } \\
\text { Hospital Mário Covas); fornecimento de hipoclorito de sódio } \\
\text { para que a Prefeitura pudesse higienizar os ambientes e ruas. }\end{array}$ & $\begin{array}{l}\text { Distribuição de álcool em gel na Rua } 13 \text { de Maio, no centro da } \\
\text { cidade; totens de álcool em gel nos terminais de ônibus; }{ }^{6} \\
\text { higienização de vias públicas com água de reuso em áreas } \\
\text { localizadas em torno de todos os hospitais de Campinas, } \\
\text { rodoviária, Mercado Municipal, Bom Prato, Farmácia de Alto } \\
\text { Custo e Paço Municipal; campanhas de conscientização das } \\
\text { medidas de higiene }{ }^{7} \text { isenção de tarifa para população de baixa } \\
\text { renda com consumo de até } 10 \mathrm{~m}^{3} \text {, até dezembro de } 2020 \text {, sendo } \\
\text { que o desconto concedido durante esses meses será cobrado, de } \\
\text { maneira parcelada, nas faturas subsequentes; }{ }^{8} \text { cálculo da tarifa } \\
\text { por abastecimento de água e esgoto com base no consumo dos } \\
\text { meses de março, abril e maio de } 2019 .{ }^{9}\end{array}$ \\
\hline
\end{tabular}

Fonte: elaboração própria, 2021, a partir de informações fornecidas pela SABESP, através da Lei de Acesso à Informação, e indicadas no sítio eletrônico da SANASA.

${ }^{4}$ HORTOLÂNDIA (Município). Plano Municipal de Saneamento Básico do Município de Hortolândia / SP. Volume IV. Humanizar Consultoria, 2015.

${ }^{5}$ CAMPINAS (Município). Plano Municipal de Saneamento Básico. Produto 3: Programas e Ações. Campinas, 2013.

6 SANASA. Sanasa distribui álcool em gel à população. 2020.

7 SANASA. Sanasa higieniza vias públicas com água de reúso. 2020.

${ }^{8}$ SANASA. Sanasa estende isenção da cobrança da tarifa para população de baixa renda. 2020

9 SANASA. Nota Sanasa - Coronavírus - Recomendações do Sr. Prefeito Jonas Donizette. 2020. 
No Quadro 1 vê-se que os planos de saneamento vigentes nas cidades estudadas não consideram como emergências situações que vão além dos aspectos técnicos, pois se preocupam com a infraestrutura já existente. A garantia de água durante emergências que possam colocar os carentes em saneamento em maior vulnerabilidade não está presente nos planos, razão pela qual se entende que não seriam suficientes para combater a pandemia de Covid-19.

No caso de Campinas, há preocupação com a continuidade dos serviços, o que pressupõe a existência da infraestrutura. O Plano Municipal de Saneamento vigente, datado de 2013, não permite visualizar quais seriam as respostas a serem adotadas pela SANASA, porquanto foram definidas por meio de código internos, cujos significados não foram identificados no próprio plano ou no sítio eletrônico da prestadora. Entende-se que: a) o plano não é exequível para as emergências que extrapolam os aspectos técnicos, não obrigando a SANASA a atuar frente às outras situações; b) não atende as pessoas carentes em água potável, na medida em que não prevê fornecimento emergencial para as áreas onde essa população reside; c) o plano de saneamento falhou ao não prever emergências não técnico-operacionais, já que a cidade sofreu com epidemia de dengue em 2007, anos antes da elaboração do plano vigente. Já o Plano Municipal Integrado de Gerenciamento de Assistência Humanitária para Situações de Desastres, mencionado no plano de saneamento, ainda que aponte o fornecimento de água potável às vítimas de desastre como uma resposta a ser adotada, não indica a quantidade por pessoa e não imputa diretamente à SANASA esta responsabilidade.

O plano de saneamento de Hortolândia, embora não elenque qualquer tipo de emergência, entende que as respostas devem se relacionar aos aspectos técnicos que visam modernizam e monitorar o sistema já existente. Não se preocupa em fornecer, emergencialmente, água àqueles que não têm acesso. Também não é exequível em urgências desassociadas dos aspectos técnico-operacionais e não direciona a atuação da prestadora para desastres nos quais o fornecimento de água é uma das medidas para diminuir o grau de vulnerabilidade das pessoas com baixa capacidade de resposta.

O Quadro 2 demonstra que todas as ações adotadas no combate a pandemia não têm relação com o disposto nos Planos Municipais de Saneamento. Em Campinas, as respostas da SANASA: a) se concentraram na região central da cidade, onde há acesso à água potável. Não foram adotadas ações específicas em locais carentes em água potável ou com acesso precário; b) privilegiaram o nível de consumo, pois a isenção tarifária considerou o consumo e não a capacidade econômica do usuário; c) se encerraram ainda com a pandemia em curso. Em Hortolândia, o acesso à água emergencial se daria apenas por meio de lavatórios instalados no hospital e nas unidades de pronto atendimento, possibilitando a lavagem das mãos, mas não a higienização pessoal. As demais ações anunciadas pela SABESP em seu site, como isenção tarifária para usuários da tarifa social, não foram apontadas na resposta fornecida diretamente pela prestadora, por meio da Lei de Acesso à Informação.

Em ambas as cidades, a população mais pobre, que habita moradias precárias e são carentes em saneamento, não aparece como prioridade nos planos de saneamento e nem nas ações de combate à pandemia, aumentando sua vulnerabilidade frente à propagação do vírus.

\section{CONCLUSÃO}

Conclui-se que, a despeito da importância de respostas emergenciais voltadas aos aspectos técnicos e operacionais do sistema já existentes, as emergências que merecem resposta por parte das prestadoras não estão restritas a isso, podendo se relacionar aos fatos nos quais o fornecimento de água emergencial pode diminuir a vulnerabilidade das pessoas carentes em saneamento.

Os Planos Municipais de Saneamento precisam de revisão, para que as matrizes adotadas não sejam apenas tecnológicas, incluindo como público-alvo das emergências a população carente em água potável ou que tem acesso precário. Essa modificação da matriz permitiria: a) estabelecer melhor as 
obrigações das prestadoras frente às emergências, possibilitando a exigência do cumprimento do seu dever; b) traçar respostas que visem atender os espaços onde o acesso à água potável é inexistente ou precário e de uma forma que tragam exequibilidade ao plano emergencial, elencando prazos, volume mínimo a ser fornecido gratuitamente e estabelecendo os pontos estratégicos para instalação de estrutura com água potável gratuita.

\section{AGRADECIMENTOS}

O presente trabalho foi realizado com apoio da Coordenação de Aperfeiçoamento de Pessoal de Nível Superior - Brasil (CAPES) - Código de Financiamento 001.

\section{REFERÊNCIAS BIBLIOGRÁFICAS}

AGÊNCIA METROPOLITANA DE CAMPINAS. Plano de Desenvolvimento Urbano Integrado: Região Metropolitana de Campinas. Campinas: AGEMCAMP, 2018, 178p. (Relatório 2 Diagnóstico Preliminar dos Problemas Metropolitanos). Disponível em <http://multimidia.pdui.sp.gov.br/rmc/docs-pdui/rmc_docspdui_0010.pdf>. Acesso: set. 2021;

BRASIL. Lei Federal n ${ }^{\circ} 11.445 / 07$. Estabelece diretrizes nacionais para o saneamento básico; cria o Comitê Interministerial de Saneamento Básico; altera as Leis nos 6.766, de 19 de dezembro de 1979, 8.666, de 21 de junho de 1993, e 8.987, de 13 de fevereiro de 1995; e revoga a Lei $\mathbf{n}^{\mathbf{0}}$ 6.528, de 11 de maio de 1978. Brasília, Janeiro, 2007;

BRASIL. Lei Federal $\mathrm{n}^{\circ}$ 12.527/11. Regula o acesso a informações previsto no inciso XXXIII do art. $5^{\circ}$, no inciso II do $\S 3^{\circ}$ do art. 37 e no $\S 2^{\circ}$ do art. 216 da Constituição Federal; altera a Lei $n^{\circ}$ 8.112, de 11 de dezembro de 1990; revoga a Lei $n^{\circ} 11.111$, de 5 de maio de 2005, e dispositivos da Lei $n^{\circ}$ 8.159, de 8 de janeiro de 1991; e dá outras providências. Brasília, 18 de novembro de 2011;

CAMPINAS (Município). Plano Municipal de Habitação de Campinas. Campinas, SP: Secretaria Municipal de Habitação -SEHAB, 2011. Disponível em <https://www.campinas.sp.gov.br/governo/habitacao/plano-habitacao.php>. Acesso: set. 2021;

FREITAS, C. et al. COVID-19 as a global disaster: Challenges to risk governance and social vulnerability in Brazil. Ambiente e sociedade, v. 23, p. 1 - 12, 2020.

FUndaÇÃo naCiOnAL DE SAÚde (FUnASA). Política e Plano Municipal de Saneamento Básico: convênio Funasa/Assemae. 2. ed. - Brasília: Funasa, 2014. Disponível em < https://bvsms.saude.gov.br/bvs/publicacoes/politica_plano_municipal_saneamento_basico_2_ed.pd f>. Acesso: set. 2021;

FURIGO, R. Universalização do saneamento no contexto dos assentamentos precários urbanos brasileiros. PUCC, Tese - Doutorado em Urbanismo. Campinas, 2020.

HELLER, L. Política pública e gestão dos serviços de abastecimento de água e esgotamento sanitário e suas interfaces: a perspectiva da saúde pública. In: HELLER, L.; CASTRO, J. E (org,). Política pública e gestão de serviços de saneamento. Edição ampliada. Belo Horizonte: Editora UFMG; Rio de Janeiro: Editora Fiocruz, 2013;

MORETTI, R. et al. O direito à água potável e os riscos de desabastecimento. Revista da Universidade Federal de Minas Gerais, v. 20, p. 291-305, 2013. Disponível em < https://www.ufmg.br/revistaufmg/downloads/20-2/14-o-direito-a-agua-potavel-e-os-riscos-dedesabastecimento-ricardo-moretti-leonardo-varallo-francisco-comaru.pdf >. Acesso: set. 2021. 